\title{
Stimulasi Keterampilan Proses Sains Anak Melalui Model Pembelajaran Sains Berbasis Proyek
}

\author{
Niken Farida
}

Universitas Sari Mutiara, Banjarmasin, Kalimantan Selatan, Indonesia

INFORMASI

Artikel Histori:

Diterima :

$19 / 11 / 2020$

Direvisi :

$14 / 01 / 2021$

Diterbitkan:

20/01/2021

\section{Keywords: \\ Early childhood, \\ Project-based \\ science learning, \\ Science process \\ skill}

Kata Kunci:

Anak usia dini,

Model

pembelajaran

sains berbasis

proyek,

Keterampilan

proses sains

\section{DOI:}

https://doi.org

/10.46963/mas

h.v4i01.222

\section{Korespondensi \\ Penulis: \\ Niken Farida \\ nikenfarida16@ \\ gmail.com}

\begin{abstract}
This study aims to improve the science process skills of children aged 5-6 years through a project-based learning model. This research is a type of quasy experiment with an equivalent time series design. The research subjects consisted of 88 group children, namely children aged 5-6 years from 6 Kindergartens in Sleman Regency. Data collection was carried out using observation. Then the data were analyzed using one way ANOVA and got the sig value. 0.00 , which means that there is a difference in the mean ranking of process science skills after using a project-based science learning model, so the results of this study indicate that an effective project-based science learning model is used to improve science process skills of children aged 5-6 years.
\end{abstract}

ABSTRAK: Penelitian ini bertujuan untuk meningkatkan keterampilan proses sains anak usia 5-6 tahun melalui model pembelajaran berbasis proyek. Penelitian ini merupakan jenis quasi-eksperimen dengan desain time series jenis equivalent time series. Subjek penelitian ini terdiri dari 88 anak kelompok B yaitu anak yang berusia 5-6 tahun yang berasal dari 6 TK di kabupaten Sleman. Pengumpulan data yang dilakukan menggunakan observasi. Kemudian data dianalisis menggunakan one way ANOVA dan mendapatkan nilai sig. 0,00 yang artinya terdapat perbedaan peringkat rerata pada ketrampilan sains proses anak setelah menggunakan model pembelajaran sains berbasis proyek, sehingga hasil penelitian ini menunjukkan bahwa model pembelajaran sains berbasis proyek efektif digunakan untuk meningkatkan keterampilan proses sains anak usia 5-6 tahun.

\section{Cara mensitasi artikel: (APA 6 Style)}

Farida, N. (2021). Stimulasi Keterampilan Proses Sains Anak Melalui Model Pembelajaran Sains Berbasis Proyek. Mitra Ash-Shibyan: Jurnal Pendidikan dan Konseling, 04(01), 71-80. https://doi.org/10.46963/mash.v4i01.222 


\section{PENDAHULUAN}

Pembelajaran sains pada anak usia dini memiliki peranan yang sangat penting dalam membantu meletakkan dasar kemampuan dan pembentukan sumber daya manusia yang diharapkan. Pembekalan sains penting dilakukan pada individu sejak dini agar pengalaman awal sains pada setiap anak dapat difasilitasi dan berkembang sesuai dengan yang diharapkan. Sains secara sederhana merupakan suatu kegiatan yang memberikan anak kesempatan untuk mengeksplorasi, bertanya dan belajar mengenali lingkungan terdekat anak melalui pengalaman aktif dan langsung yang dialami oleh anak. Sains bagi anak-anak merupakan segala sesuatu yang menakjubkan, sesuatu yang ditemukan yang dianggap menarik serta memberi pengetahuan atau merangsangnya untuk mengetahui dan menyelidiki (Perdaningsari \& Kristanto, 2014).

Di samping itu, tujuan pembelajaran sains adalah agar menekankan pentingnya pembelajaran sains untuk anak usia dini. Leeper di dalam (Putra, 2013) mengemukakan tujuan pengembangan sains bagi anak usia dini adalah sebagai berikut (a) agar anak-anak memiliki kemampuan memecahkan masalah yang dihadapinya melalui penggunaan metode sains, sehingga anak-anak terbantu dan menjadi terampil dalam menyelesaikan berbagai hal yang dihadapinya. (b) Agar anak memiliki sikap ilmiah. Hal-hal yang mendasar, misalnya: tidak cepat dalam mengambil keputusan, dapat melihat sesuatu dari berbagai sudut pandang, berhati-hati terhadap informasi yang diterimanya serta bersifat terbuka (c) agar anak-anak mendapatkan penngetahuan dan informasi ilmiah yang lebih baik dan dapat dipercaya, artinya informasi yang diperoleh anak berdasarkan pada standar keilmuan yang semestinya, karena informasi yang disajikan merupakan hasil temuan dan rumusan yang obyektif serta sesuai dengan kaidah kaidah keilmuan yang menaunginya (d) agar anak lebih berminat dan tertarik untuk menghayati sains yang berada dan ditemukan di lingkungan dan alam sekitarnya. Hal ini juga memberikan anak kesempatan untuk terlibat dalam kegiatan dikehidupan sehari-hari dan masyarakat (Jain, Lim, \& Abdullah, 2013).

Ketika kita ingin memperkenal sains untuk anak usia dini pastikan bahwa memberikan anak kesempatan untuk bermain dan berekplorasi menggunakan benda konkrit sehingga kegiatan menjadi lebih menarik. Analisis untuk membuat kegiatan pembelajaran sains untuk anak usia dini dapat menggunakan beberapa pertanyaan berikut 
ini: (1) apakah anak tertarik?, (2) apakah tugas itu terlalu mudah atau teralalu sulit? (3) Apakah anak mengerti apa yang diminta untuk dilakukan?, (4) apakah materi yang tepat untuk kegiatan pembelajaran sains anak usia dini? (5) Apakah bahan yang digunakan menarik?. kita dapat menimbang hal-hal tersebut untuk merancang kegiatan pembelajaran sains (Charlesworth \& Lind, 1979). Semakin dini anak mendapatkan pengalaman sains dapat membentuk sikap positif terhadap sains di jenjang pendidikan yang akan datang. Sehingga dapat minat anak pada sains di pendidikan selanjutnya (Broström, 2015).

Sains terbagi dua yaitu sains produk dan proses, sebagai produk sains merupakan batang tubuh pengetahuan yang terorganisir dengan baik mengenai dunia fisik dan alami, sebagai proses sains merupakan kegiatan menelusuri, megamati, dan melakukan percobaan (Hesti \& Somantri, 2015). Kemampuan yang penting dan perlu dikenalkan sejak anak usia dini dalam pembelajaran sains adalah keterampilan proses sains. Hasil belajar sains melalui proses sains menghasilkan kesan yang lama, tidak mudah dilupa, dan akan dapat digunakan sebagai dasar untuk memecahkan masalah yang akan dihadapi dalam kehidupan sehari-hari (Bundu, 2013).

Keterampilan proses sains ada tiga yaitu keterampilan proses dasar, menengah, dan lanjutan. Keterampilan proses dasar yaitu keterampilan yang paling tepat untuk anak prasekolah yang meliputi mengamati (observing), membandingkan (comparing), mengklasifikasi (classifying), pengukuran (measuring), dan mengkomunikasikan (communicing). Sedangkan keterampilan menengah adalah keterampilan yang sesuai untuk jenjang yang pendidikan yang lebih tinggi yang meliputi menyimpulkan (inferring) dan memprediksi (predicting). Terakhir adalah keterampilan proses lanjutan meliputi hipotesa (hypotheses), mendefinisikan (defining) and mengontrol variabel (controlling variable) (Charlesworth \& Lind, 1979).

Pedoman Standart Pembelajaran Sains untuk anak usia dini yaitu (Jacobs \& Crowley, 2007): (a) Science as Inquiry memiliki 2 kemampuan anak yang di tekankan yaitu kemampuan anak melakukan penyelidikan dan pemahaman yang harus dimiliki untuk melakukan penyilidikan ilmiah (b) Physical Science mengembangakan pemahaman anak tentang sifat-sifat benda, bahan, posisi, gerakan benda seperti cahaya, panas, listrik dan magnet. (c) Life science mengembangkan pemahaman anak

mitra Ash-Shibyan: Jurnal Pendidikan dan Konseling | Vol. 04, No. 01 (2021) 73 
tentang karakteristik makhluk hidup, siklus hidup, serta lingkungan hidup (d) Earth and Space Science mengembangkan pemahaman anak tentang sifat bahan bumi, benda langit, dan perubahan di bumi dan langit. (e) Science and Technology Education mengembangkan pemahaman anak tentang kemampuan untuk membedakan objek alam dan benda yang dibuat oleh manusia. (f) Science in Personal and Social Perspective mengembangkan pemahaman anak tentang kesehatan pribadi, perubahan populasi, jenis sumber daya dan perubahan lingkungan sehingga anak anak mampu menunjukkan kesadaran dan peduli lingkungan.

Berdasarkan hasil observasi yang telah dilakukan keterampilan proses sains pada anak yang masih belum optimal meliputi keterampilan mengamati, membandingkan, mengukur dan mengkomunikasi. Hal ini ditunjukkan dengan masih terdapat anak yang belum optimal melakukan aktivitas yang bersifat eksploratif. Pada keterampilan mengamati terdapat anak yang belum mampu mengidentifikasi ciri suatu benda, mengidentifikasi perbedaan dan persamaan benda, mengurutkan dan memberikan uraian tentang benda dan peristiwa tertentu. Pada keterampilan mengukur, masih terdapat anak yang belum mampu mengukur dan menggunakan satuan ukuran yang tidak baku. Begitu pula keterampilan membandingkan masih terdapat anak yang belum mampu untuk membandingkan objek seperti, volume, warna dan berat. Sedangkan dalam keterampilan mengkomunikasikan, anak belum mampu menyampaikan pengetahuannya baik secara lisan maupun tulisan kepada guru, teman sebaya, dan orang dewasa lainnya.

Berdasarkan hasil PISA (Programme for Internasional Student Assessment) (2012), kemampuan anak Indonesia di bidang matematika, sains, dan membaca masih rendah dibandingkan dengan anak-anak lain di dunia. Indonesia berada diperingkat ke-64 dari 65 negara yang berpartisipasi dalam tes. Rata-rata skor matematika anak-anak Indonesia 375, rata-rata skor membaca 396, dan rata-rata skor untuk sains 382. Kondisi tersebut harus segera diatasi mengingat eksistensi dan perkembangan suatu bangsa terletak pada kualitas sumber daya manusianya bukan pada kualitas sumber daya alamnya. Dari data tersebut mendorong perlunya untuk meningkatkan kualitas sumber daya manusia melalui pendidikan anak usia dini (Direktorat Pembinaan Pendidikan Anak Usia Dini, 2015). Dari sisi waktu yang dihabiskan untuk kegiatan belajar perhari fokus pada bahasa dan keaksaraan (17\%), sosial

74 mitra Ash-Shibyan: Jurnal Pendidikan dan Konseling | Vol. 04, No. 01 (2021) Licensed under CC-BY-SA (c) (1) () 
$(15 \%)$, dan seni $(15 \%)$. sains (11\%) dan matematika (8\%) masing masing kegiatan memiliki bagian yang kecil. Kegiatan tersebut tidak berdiri sendiri melainkan setiap kegiatan saling berkaitan seperti literasi dan sains. Berdasarkan hal ditas sains mendapatkan porsi kedua terkecil setelah matematika.

Berdasarkan paparan diatas perlunya suatu upaya untuk meningkatkan keterampilan proses sains pada anak usia dini. Salah satunya melalui model pembelajaran sains berbasis proyek. Model pembelajaran ini merupakan pengembangan dari model pembelajaran berbasis proyek yang secara khusus didesain untuk mengembangkan keterampilan sains proses anak. Project Based Learning adalah sebuah metode belajar mengajar dan inovatif yang melibatkan siswa dalam kegiatan penelitian untuk memecahkan proyek yang relevan yang memungkinkan siswa untuk bekerja secara independen untuk membangun pengetahuan mereka berdasarkan proyek yang melibatkan situasi nyata (Dos, Gonçalves, Oliveira, \& Silva, 2018).

Pembelajaran berbasis proyek adalah pendekatan yang sangat efektif yang memungkinkan siswa untuk mengeluarkan pendapat tentang topik yang mencakup minat, untuk mengajukan pertanyaan, untuk memperkirakan, untuk mengembangkan teori, untuk menggunakan alat yang berbeda (Du \& Han, 2016), sehingga dalam pendekatan ini anak berhak untuk memilih kegiatan, aktif dan kegiatan berpusat pada anak. Penggunaan pendekatan proyek memenuhi karakteristik anak-anak yang suka mengeksplorasi dan menekankan pentingnya pembelajaran berbasis pengalaman, memberikan anak untuk terlibat secara aktif dengan metode pemebelajaran yang berpusat pada anak (Rahman, M. Yasin, \& M, 2012).

Stoller dalam (Du \& Han, 2016) mengemukakan kriteria project based learning sebagai berikut: (1) memiliki suatu proses dan produk; (2) memberi anak sebuah proyek (3) memiliki periode waktu yang panjang (beberapa hari, minggu, atau bulan); (4) mengintegrasikan keterampilan; (5) mengembangkan pemahaman siswa tentang suatu topik melalui integrasi bahasa dan isi; (6) berkolaborasi dengan siswa dan bekerja sendiri; (7) memegang siswa bertanggung jawab atas pembelajaran mereka sendiri melalui pemrosesan, dan pelaporan informasi dari sumber daya target bahasa; (8) menetapkan peran baru dan tanggung jawab kepada siswa dan guru; (9) menyediakan produk akhir yang nyata; dan (10) merefleksikan proses dan Produk. 


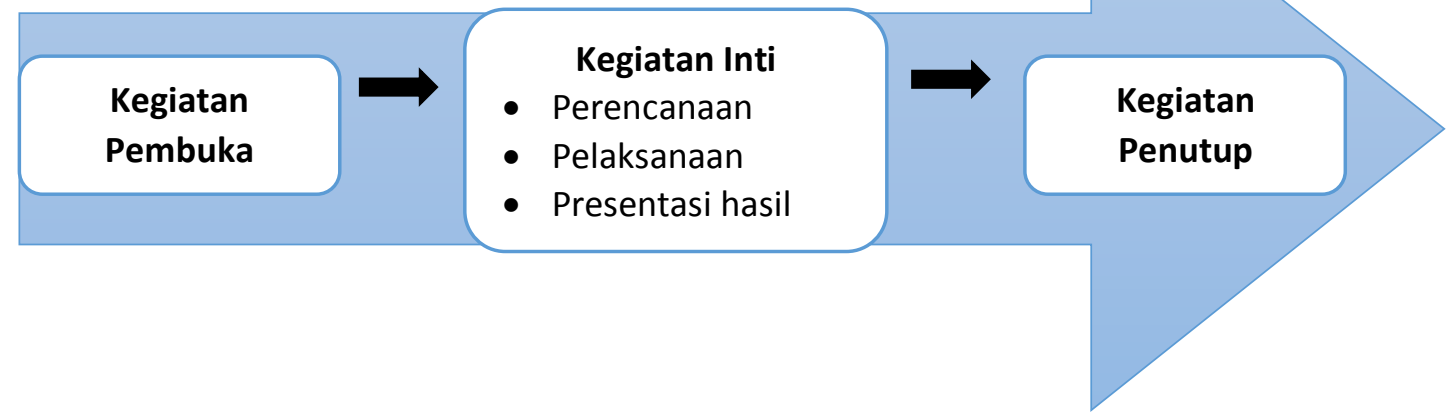

Gambar 1. Langkah-langkah (syntax) model pembelajaran sains berbasis proyek

Kegiatan model pembelajaran sains berbasis proyek terdiri dari kegiatan pembuka, kegiatan inti yang terdiri dari kegiatan proyek yang terbagi menjadi 3 tahap yaitu tahap perencanaan proyek, tahap pelaksanaan proyek, tahap mempresentasikan hasil, yang terakhir adalah kegiatan penutu. Langakah -langkah pelaksanaan model pembelajaran sains berbasis peroyek: (a) Kegiatan Pembuka guru membuka pembelajaran dengan sebuah pertanyaan dengan memberikan pertanyaan yang mengarahkan anak untuk berfikir kritis (b) Kegiatan Inti terdiri dari tahap perencanaan proyek, tahap pelaksanaan proyek dan presentasi hasil proyek (produk) yang telah dibuat. (c) Kegiatan penutup guru melakukan penilaian terhadap produk yang telah dibuat dan memberikan kesimpulan terkait kegiatan yang telah dilakukan.

\section{METODE PENELITIAN}

Penelitian ini merupakan penelitian kuantitatif menggunakan metode quasi eksperiment dengan desain time-series. Time series yaitu menganalisis sesuatu berdasarkan pengamatan, pencatatan, dan peristiwa yang diperoleh dari waktu ke waktu (Hadi, 2015). Desain time series hanya memerlukan satu kelompok uji coba untuk diamati tanpa adanya kelompok kontrol sehingga desain ini tidak memerlukan subjek dengan jumlah yang banyak (Creswell, 2012). Desain time series yang digunakan dalam penelitian ini adalah equivalent time series design, dimana peneliti memberikan perlakuan dalam jangka waktu tertentu kemudian hasil pengukuran (posttest) dibandingkan untuk melihat pola dari waktu kewaktu.

Penelitian ini memberikan perlakuan sebanyak 5 kali dan kemudian dianalisis menggunakan uji uji one way ANOVA. Subjek dalam

76 mitra Ash-shibyan: Jurnal Pendidikan dan Konseling | Vol. 04, No. 01 (2021) Licensed under CC-BY-SA (c) (1) () 
penelitian ini adalah 88 anak usia 5-6 tahun. Instrumen yang digunakan berupa lembar observasi keterampilan sains proses anak usia 5-6 tahun yang terdiri dari 4 aspek dengan 9 item pernyataan. Hasil uji one way ANOVA mendapatkan nilai sig. 0,00 menunjukkan terdapat perbedaan peringkat rerata pada model pembelajaran sains berbasis proyek sehingga model pembelajaran sains berbasis proyek dapat meningkatkan keterampilan proses sains anak usia 5-6 tahun.

\section{HASIL DAN PEMBAHASAN}

Keterampilan sains proses yang dinilai dalam penelitian ini terdiri dari 4 aspek yaitu mengamati, membandingkan, mengukur, dan mengkomunikasikan. Berikut hasil rekapitulasi perbandingan seluruh rerata pada aspek kemampuan sains proses.

Tabel 1. Perbandingan Rerata Seluruh Aspek Keterampilan Proses Sains

\begin{tabular}{ccccccc}
\hline & \multicolumn{5}{c}{ Aspek Penilaian } & Rerata \\
\cline { 2 - 6 } O & $\begin{array}{c}\text { Meng } \\
\text { amati }\end{array}$ & $\begin{array}{c}\text { Membandin } \\
\text { gkan }\end{array}$ & Mengukur & $\begin{array}{c}\text { Mengkom } \\
\text { unikasikan }\end{array}$ & Akhir & Persentase \\
\hline O1 & 386 & 361 & 156 & 624 & 17,35 & $14,8 \%$ \\
\hline O2 & 397 & 377 & 180 & 747 & 19,33 & $16,5 \%$ \\
\hline O3 & 432 & 431 & 222 & 866 & 22,17 & $18,9 \%$ \\
\hline O4 & 599 & 497 & 244 & 931 & 25,81 & $22,0 \%$ \\
\hline O5 & 647 & 673 & 302 & 1247 & 32,60 & $27,8 \%$ \\
\hline
\end{tabular}

Berdasarkan tabel rekapitulasi rerata seluruh aspek maka dapat dilihat terjadi peningkatan skor dan persentase dari treatment 1 hingga treatmen 5 .

Setelah mengetahui ada peningkatan rerata dari treatmen 1 hingga treatmen 5. Selanjutnya melakukan analisis dengan menggunakan SPSS 22.0. SPSS 22 digunakan untuk melihat perbedaan rerata dari setiap aspek keterampilan proses sains, dari analisis tersebut diperoleh grafik time series nilai rerata yang sesuai dengan hasil perkembangan anak. Berikut ini hasil analisis time series. 


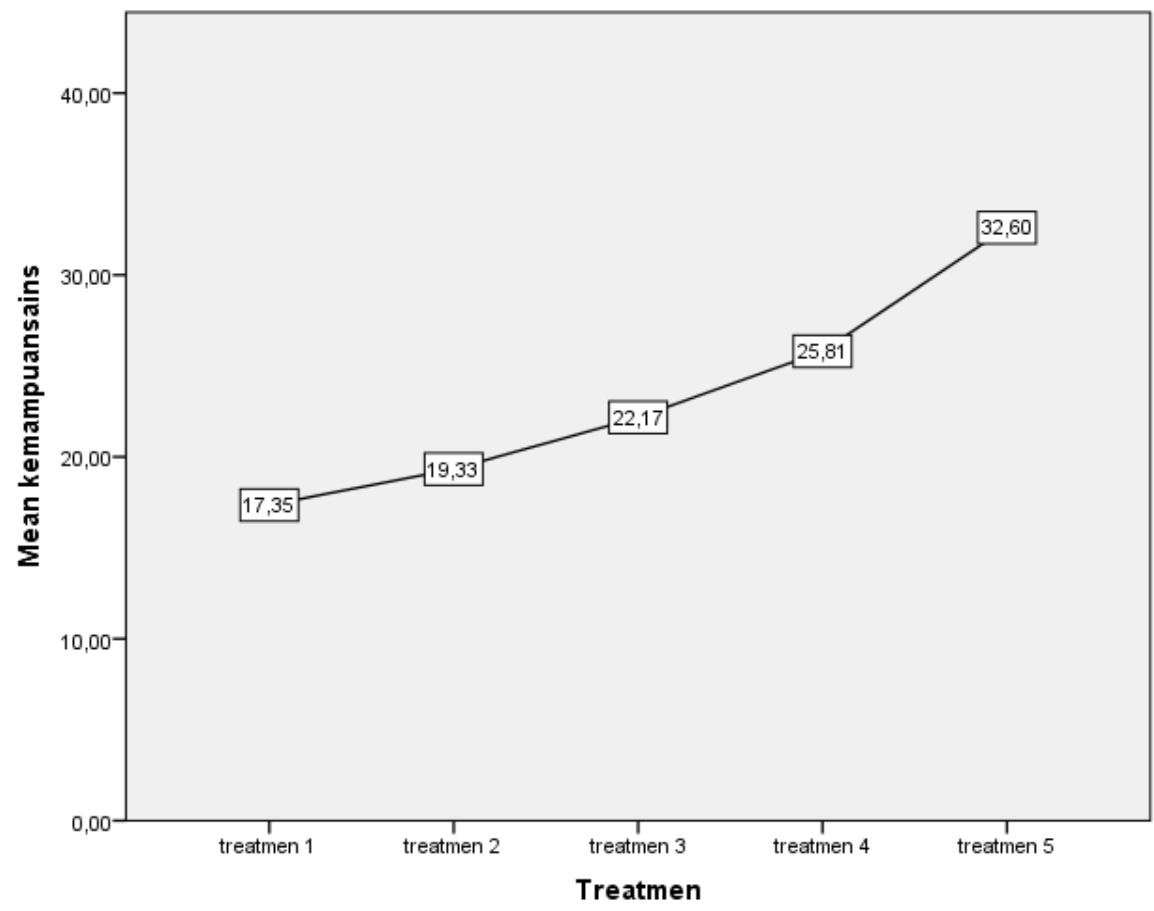

Grafik 1. Time Series Rerata Keterampilan Proses Sains

Tabel 1. Ranks Hasil Uji Efektivitas

\begin{tabular}{llcc}
\hline & Treatment & N & Mean Rank \\
\hline \multirow{4}{*}{ Kemampuan } & Treatment 1 & 88 & 75,30 \\
\cline { 2 - 3 } Sains & Treatment 2 & 88 & 130,84 \\
\cline { 2 - 3 } & Treatment 3 & 88 & 210,60 \\
\cline { 2 - 3 } & Treatment 4 & 88 & 290,55 \\
\cline { 2 - 3 } & Treatment 5 & 88 & 395,20 \\
\cline { 2 - 3 } & Total & $\mathbf{4 4 0}$ & \\
\hline
\end{tabular}

Berdasarkan tabel tersebut terdapat perbedaan peringkat rerata di setiap treatmen yang dilakukan. Peringkat rerata tertinggi sebesar 395,20 berada pada treatment 5 sedangkan rerata terendah sebesar 75,30 berada pada treatment 1.

Tabel 1. Hasil Uji ANOVA

\section{ANOVA}

\begin{tabular}{|l|c|r|r|r|r|}
\hline & kelompok \\
& Sum of & \multicolumn{1}{c|}{ df } & Mean Square & F & Sig. \\
\hline Between Groups & 717.977 & 23 & 31.216 & 80.149 & .000 \\
Within Groups & 162.023 & 416 & .389 & & \\
Total & 880.000 & 439 & & & \\
\hline
\end{tabular}

78 mitra Ash-shibyan: Jurnal Pendidikan dan Konseling | Vol. 04, No. 01 (2021) Licensed under CC-BY-SA 
Berdasarkan tabel tersebut maka diperoleh sig sebesar 0,000 yang berarti $\mathrm{p}<0,05$, kesimpulannya adalah Ha diterima dan Ho ditolak. Sehingga terdapat perbedaan yang signifikan pada rerata peringkat keterampilan proses sains anak setelah diberikan treatmen berupa model pembelajaran sains berbasis proyek. Dengan demikian dapat dinyatakan bahwa model pembelajaran sains berbasis proyek dapat meningkatkan keterampilan proses sains untuk anak usia 5-6 tahun.

\section{SIMPULAN}

Hal yang dibutuhkan untuk meningkatkan keterampilan proses sains anak usia 5-6 tahun adalah (a) perlunya sebuah model pembelajaran sains berbasis proyek sehingga dapat meningkatkan keterampilan proses sains anak usia 5-6 tahun, (a) anak membutuhkan kegiatan yang memberikan kesempatan untuk bereksplorasi melalui pengalaman yang menarik, (c) kegiatan yang bervariasi agar tidak monoton, kegiatan yang melibatkan panca indera seperti mengamati, mengukur, membandingkan dan mengkomunikasikan.

Model pembelajaran sains berbasis proyek efektif untuk meningkatkan keterampilan proses sains anak usia 5-6 tahun. Model pembelajaran sains berbasis proyek memberikan anak kesempatan anak untuk bereksplorasi membangun pengetahuannya dan memberikan pengalaman yang bermakna melalui hal yang konkrit dan rill sehingga guru tidak mengintervensi anak dalam proses pembelajaran. Model pembelajaran sains berbasis proyek memberikan alternatif kegiatan sains yang dikemas secara menarik, menggunakan alat dan bahan yang terjangkau dan sesuai dengan karakteristik anak usia dini. Pelaksanaannya terdiri dari kegiatan pembuka, kegiatan inti yang terdiri dari kegiatan proyek yang terbagi menjadi 3 tahap yaitu tahap perencanaan proyek, tahap perancanaan proyek, tahap mempresentasikan hasil, yang terakhir adalah kegiatan penutup.

\section{DAFTAR PUSTAKA}

Broström, S. (2015). Science in Early Childhood Education. Journal of Education and Human Development, 4(2), 1.

Bundu, P. (2013). Penilaian Keterampilan Proses dan Sikap Ilmiah Dalam Pembelajaran Sains SD. Jakarta: Depdiknas.

Charlesworth, R., \& Lind, K. K. (1979). Math and Science for young Children. New York: Delmar Publishing. 
Creswell, J. (2012). Educational Research: Planing, Conducting, and Evaluating Quantitative and Qualitative Research (4 ed.). United States of America: Pearson.

Direktorat Pembinaan Pendidikan Anak Usia Dini. (2015). Kurikulum Pendidikan Anak Usia Dini, Apa, Mengapa, dan Bagaimana. Jakarta: Direktorat Pembinaan Pendidikan ANak Usia DIni.

Dos, S. E., Gonçalves, B. C., Oliveira, K. B., \& Silva, M. B. (2018). Project Based Learning Applied to Technical Drawing. Education, 9, 479-496.

Du, X., \& Han, J. (2016). A Literature Review on the Definition and Process of Project-Based Learning and Other Relative Studies. Creative Education, 7(07), 1079.

Hadi, S. (2015). Statistika. Yogyakarta: Pustaka Pelajar.

Hesti, D., \& Somantri, E. B. (2015). Penerapan Pembelajaran Sains dalam mengembangkan Kemampuan Matematika Anak Usia 4-5 Tahun di Pendidikan Anak Usia Dini Sasana Balita Puspita Pontianak. Jurnal Edukasi Pendidikan Anak Usia Dini, 4(2).

Jacobs, G., \& Crowley, K. (2007). Jacobs, G., \& CrPlay, Projects, and Preschool Standards: Nurturing Children's Sense of Wonder and Joy in Learning. Corwin Press.

Jain, J., Lim, B. K., \& Abdullah, N. (2013). Pre-service Teachers' Conceptions of The Nature of Science. Procedia-Social and Behavioral Sciences, 90, 203-210.

Perdaningsari, A. P., \& Kristanto, A. (2014). Pengaruh Model Pembelajaran Inkuiri Terhadap Kemampuan Sains Anak Kelompok A di Taman Kanakkanak ABA. PAUD Teratai, 3(3).

Putra, S. R. (2013). Desain Belajar Mengajar Kretaif Berbasis Bisnis. Yogyakarta: Diva Press.

Rahman, S., M. Yasin, R., \& M, S. F. (2012). Project-based Approach at Preschool Setting. World Applied Science Journal, 16(1), 106-112.

80 mitra Ash-Shibyan: Jurnal Pendidikan dan Konseling | Vol. 04, No. 01 (2021) Licensed under CC-BY-SA (c) (1) () 